\title{
Initially elevated arterial lactate as an independent predictor of poor outcomes in severe acute pancreatitis
}

\author{
Wenqing Shư ${ }^{\dagger}$, Jianhua Wan ${ }^{\dagger}$, Jie Chen, Wenhua He, Yong Zhu, Hao Zeng, Pi Liu, Yin Zhu, Liang Xia*
} and Nonghua Lu

\begin{abstract}
Background: The present study aimed to investigate the relationships between arterial lactate levels and outcomes in severe acute pancreatitis.

Methods: The study retrospectively analyzed the medical data of 329 patients with severe acute pancreatitis from January 2014 to February 2019. We compared baseline characteristics, laboratory data, severity scores, types of persistent organ failure, and primary and secondary outcomes of patients with and without elevated arterial lactate levels at admission. A multivariate logistic regression analysis model and receiver operating characteristic curve were adopted to evaluate the value of arterial lactate $\geq 4 \mathrm{mmol} / \mathrm{L}$ for identifying high-risk patients. Trends in arterial lactate levels were compared between patients in the survivor and nonsurvivor groups over a period of 7 days.

Results: Compared to normal arterial lactate levels, patients with elevated arterial lactate levels show significantly higher incidences of multiple persistent organ failure ( $3 \%$ vs $30 \%, P<0.01)$, death ( $2 \%$ vs $11 \%, P<0.01)$, septic shock ( $4 \%$ vs $24 \%, P<0.01)$, pancreatic infection ( $12 \%$ vs $37 \%, P<0.01)$, abdominal compartment syndrome ( $3 \%$ vs $20 \%, P<0.01)$, pancreatic necrosis ( $41 \%$ vs $63 \%, P<0.01$ ), and a need for ventilator support ( $26 \%$ vs $54 \%, P<0.01$ ). For predicting mortality, arterial lactate levels $\geq 4 \mathrm{mmol} / \mathrm{L}$ had a high hazard ratio $(10,95 \% \mathrm{Cl} ; 3.7-27 ; P<0.01)$ and the highest area under the curve (0.78).

Conclusions: Our results indicate that initially elevated arterial lactate is independently associated with poor outcomes and death in patients with severe acute pancreatitis and may serve as an early high-risk stratification indicator.
\end{abstract}

Keywords: Arterial lactate, Poor outcomes, Severe acute pancreatitis

\section{Background}

Severe acute pancreatitis (SAP) is one of the most dangerous acute inflammatory diseases in the abdomen, with the characteristics of rapid progression, serious complications and high mortality. As the most lethal classification of acute pancreatitis (AP), the $15-20 \%$ of AP patients may

\footnotetext{
*Correspondence: xialiang79@163.com

+Wenqing Shu and Jianhua Wan contributed equally to this work. Department of Gastroenterology, The First Affiliated Hospital of Nanchang University, 17 Yongwaizheng Street, Nanchang, Jiangxi 330006, PR China
}

develop into SAP and mortality in SAP patients may be as high as $30-50 \%[1-3]$. Considering the morbidity and mortality associated with SAP, the ability to identify highrisk patients in the early stages of the disease is critical because it can help clinicians institute more effective management or quickly transfer the patient to specialist care to improve the clinical prognosis.

The methods of risk stratification and prediction of severity in the early period of AP have been developed over the decades, including several clinical scoring

(c) The Author(s). 2020 Open Access This article is licensed under a Creative Commons Attribution 4.0 International License, which permits use, sharing, adaptation, distribution and reproduction in any medium or format, as long as you give appropriate credit to the original author(s) and the source, provide a link to the Creative Commons licence, and indicate if changes were made. The images or other third party material in this article are included in the article's Creative Commons licence, unless indicated otherwise in a credit line to the material. If material is not included in the article's Creative Commons licence and your intended use is not permitted by statutory regulation or exceeds the permitted use, you will need to obtain permission directly from the copyright holder. To view a copy of this licence, visit http://creativecommons.org/licenses/by/4.0/ The Creative Commons Public Domain Dedication waiver (http://creativecommons.org/publicdomain/zero/1.0/) applies to the data made available in this article, unless otherwise stated in a credit line to the data. 
systems and laboratory parameters, such as the Acute Physiology and Chronic Health Examination (APACHE II) $[4,5]$, systemic inflammatory response Syndrome (SIRS) [6, 7], blood urea nitrogen (BUN) [8-10], creatinine [11], hematocrit [10], serum calcium [9], procalcitonin [12], C-reactive protein (CRP) [13] and base excess (BE) $[9,14]$. However, as the most serious classification of AP, there are few articles concerning the poor outcomes associated with SAP. In addition, all of the above methods are complicated or lack high accuracy [15] and are therefore of restricted clinical use and are not recommended by the new Atlanta international consensus and American guidelines [1,2]. Thus, it is necessary to find a new marker or a simple scoring system to identify high-risk patients with SAP.

Lactate is a product of anaerobic metabolism of glucose and is generally considered to be a marker of tissue hypoxia. In addition, previous studies have also found that the presence of elevated arterial lactate levels reflects critical tissue hypoperfusion, which is strongly associated with increased morbidity and mortality in critically ill patients [16-21]. A recent study has shown that elevated serum lactate is a new biomarker that could be an important tool in predicting poor outcomes of AP on admission, especially in predicting death [22]. Thus, we assume that arterial lactate may be a potentially promising biomarker to risk-stratify patients with SAP. However, the association between arterial lactate levels and outcomes in SAP has not been reported to date.

Therefore, we designed a retrospective study with the aim of exploring the relationships between the levels of arterial lactate and outcomes in SAP. Furthermore, we intended to record the average arterial lactate value over 7 days between survivor and nonsurvivor groups in patients with SAP.

\section{Methods}

\section{Study design and patient population}

The present study was a retrospective analysis of adult patients diagnosed with SAP from January 2014 to February 2019 at the First Affiliated Hospital of Nanchang University. The review boards of The First Affiliated Hospital of Nanchang University center approved the study protocol (No. 2011001).

Considering the early identification of high-risk patients with SAP, patients enrolled must meet the following criteria: first episode of SAP; age less than 75 or greater than 18 years old; time from abdominal pain onset to hospital admission of less than 3 days; patient's information recorded in the database; the first arterial lactate tested within $2 \mathrm{~h}$ after hospitalization; and other biomarkers measured within $24 \mathrm{~h}$. The exclusion criteria were the following: SAP during pregnancy; patients with severe cardiopulmonary and renal disease before the development of SAP; lack of laboratory data or medical records. Based on their initial lactate measurement, patients were divided into normal and elevated groups. The specific selection process is shown in Fig. 1.

\section{Definitions}

The diagnosis of AP was based on the presence of at least two of the three following criteria [1]: characteristic abdominal pain [2]; elevation in serum amylase and/or lipase greater than three times the upper limit of normal; and [3] characteristic imaging findings of AP by abdominal computed tomography scan [1]. The patient was classified as SAP based on the presence of persistent organ failure (POF) for more than $48 \mathrm{~h}$ (defined by modified Marshall scoring system $\geq 2$ ). Organ failure included the cardiovascular, and/or pulmonary, and/or renal systems, accompanied by a systolic blood pressure $<90 \mathrm{mmHg}$ after continuous fluid resuscitation, $\mathrm{PaO}_{2} / \mathrm{FiO}_{2} \leq 300$ or the need for mechanical ventilation, serum creatinine level $>1.9 \mathrm{mg} / \mathrm{dl}$ after rehydration or hemodialysis without preexisting renal disease [1] The patient was classified as having a pancreatic infection based on the presence of gas collections in the pancreatic and/or peripancreatic tissues on contrastenhanced computed tomography or based on a positive Gram stain and culture for bacteria and/or fungi from a fine-needle aspiration biopsy, percutaneous catheter drainage, and endoscopic transluminal drainage [1]. The diagnosis of septic shock was based on Chinese guidelines for management of severe sepsis and septic shock in 2014, meeting the following criteria: hypotension caused by sepsis (systolic blood pressure $<90 \mathrm{mmHg}$ or drops more than $40 \mathrm{mmHg}$ ) after fluid therapy [23]. The definition abdominal compartment syndrome (ACS) base on the World Society of the Abdominal Compartment Syndrome. Intra-abdominal pressure. IAP measured by Indirect monitoring urinary bladder pressure via Foley bladder catheter. ACS is defined as a sustained IAP $>20 \mathrm{mmHg}$ that is associated with new organ dysfunction [24].

\section{Outcomes}

The primary outcomes in this study included death within 1 month of follow-up, septic shock, and peripancreatic infection. The secondary outcomes included abdominal compartment syndrome, pancreatic necrosis, walled-off necrosis, portal vein thrombosis, pancreatic fistula, intestinal fistula, diabetes, the rate of ventilator support, hospital stay and hospital stay in the intensive care unit (ICU). Telephone and outpatient follow-up were arranged for a month following discharge. 


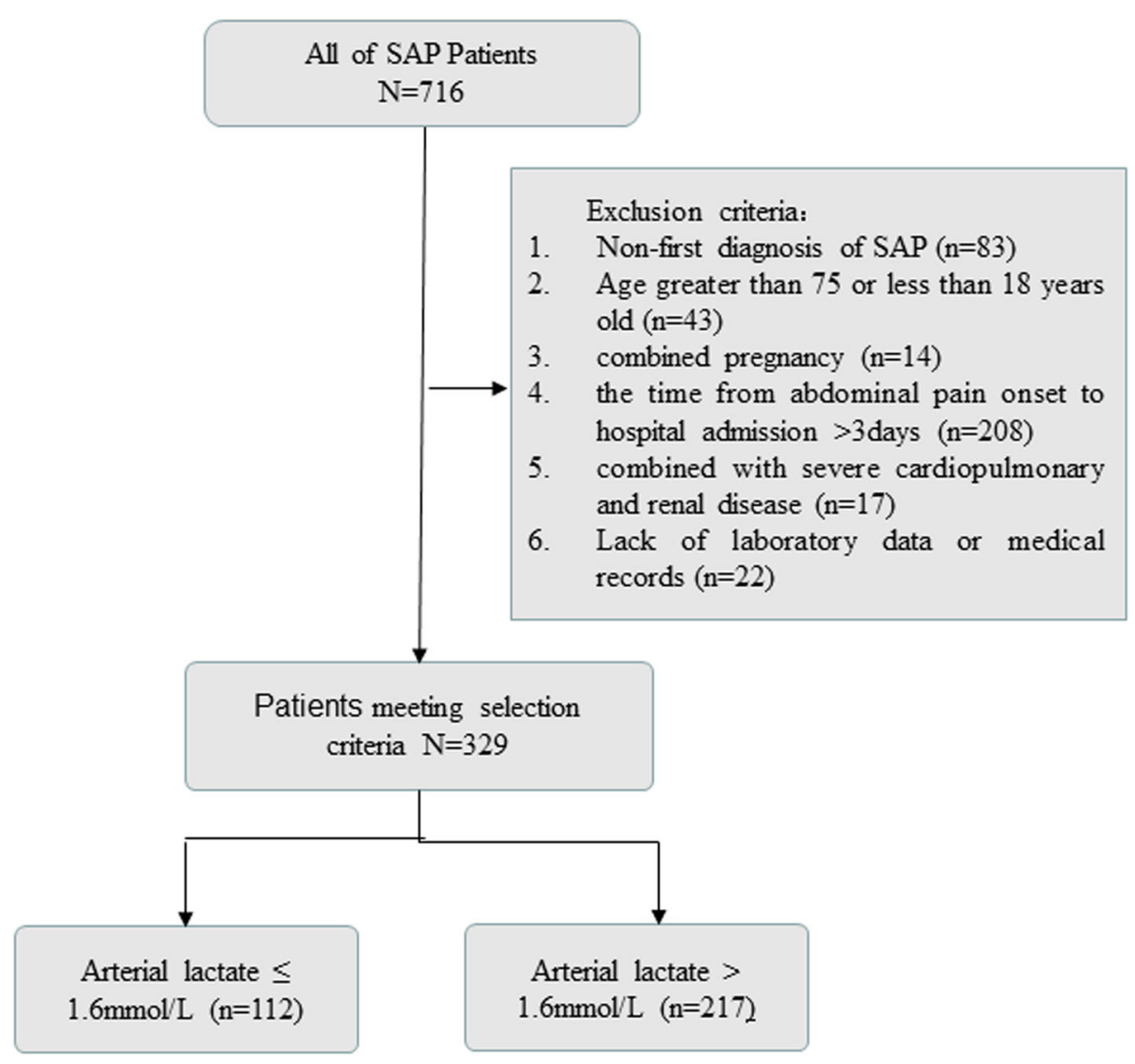

Fig. 1 Selection process and results (arterial lactate strata) for severe acute pancreatitis

\section{Statistical analysis}

Statistical analysis was performed using IBM SPSS software. Continuous data are presented as the means and interquartile range and analyzed by Student's t-test and the Mann-Whitney U test. We used the Chi-square test or Fisher exact test to analyze categorical variables and show them as numbers (frequencies). Some indicators have been further analyzed with uni- and multivariate logistic regression analyses performed with a Cox regression model and reported as the hazard ratio (HR) and 95\% confidence intervals (95\% CIs). The arterial lactate level was measured continuously for 7 days. Some patients could have multiple measurements in 1 day, in which case the highest value was used. Compared with the previous day, the recorded arterial lactate value on the next day must be separated by $6 \mathrm{~h}$. ANOVA test used to analyze multiple measurements of lactate. $P$ value $\leq 0.05$ was considered statistically significant.

\section{Results}

Baseline characteristics between patients in the normal group and the elevated group

A total of 716 patients were diagnosed with SAP, of whom 329 met the criteria for inclusion in this study
(Fig. 1). Table 1 shows the patient demographics, laboratory data and several clinical scoring systems at admission of the overall SAP population and study cohort. There were 112 SAP patients with normal arterial lactate levels and 217 SAP cases with elevated levels. The average age of the normal group was 51.8 years, and $59 \%$ of the patients were male. The mean age of the elevated group was 51.2 years, and $59 \%$ of the patients were male. There was not statistically significant difference between the normal and elevated groups in demographics (consisting of age, sex, etiology, body-mass index), partial laboratory data (such as white blood count, serum calcium, serum albumin C-reactive protein), the SIRS scores and the Balthazar grading standard. Compared with the normal group $(N=112)$, patients in the elevated group $(N=207)$ had significant differences in hematocrit $(41(36.6-46.1)$ vs $44.4(40-50)$, $P<0.01)$, serum glucose $(7.7(6.1-9.7)$ vs $10.5(8.0-$ $14.7), P<0.01)$, serum urea $(5.7(4.1-9.6)$ vs $7.7(5.6-$ $12.4), P<0.01)$, serum creatinine $\geq 1.9 \mathrm{mg} / \mathrm{dl}(10 \%$ vs $30 \%, P<0.01)$, procalcitonin $\geq 3.8 \mathrm{ng} / \mathrm{mL}(21 \%$ vs $55 \%$, $P<0.01)$, absolute value of base excess $\geq 4 \mathrm{mmol} / \mathrm{L}$ (27\% vs $65 \%, P<0.01)$ and APACHE II scores $\geq 15$ (12\% vs $25 \% P<0.01)$. 
Table 1 baseline characteristics in the 329 subjects by arterial lactate stratum

\begin{tabular}{|c|c|c|c|c|}
\hline Variable & $\begin{array}{l}\text { All patients } \\
(n=329)\end{array}$ & $\begin{array}{l}\text { Normal lactate } \\
(n=112)\end{array}$ & $\begin{array}{l}\text { Elevated lactate } \\
(n=217)\end{array}$ & $P$ value \\
\hline Age, years, (SD) & $51.4 \pm 13.8$ & $51.8 \pm 13.2$ & $51.2 \pm 14.2$ & 0.71 \\
\hline Sex (male), n (\%) & $194(59 \%)$ & $66(59 \%)$ & $128(59 \%)$ & 0.74 \\
\hline Etiology, n (\%) & & & & 0.06 \\
\hline Biliary & 161 (49\%) & $65(58 \%)$ & $96(44 \%)$ & \\
\hline Alcoholic & $42(13 \%)$ & $15(13 \%)$ & $27(12 \%)$ & \\
\hline Hyperlipidemia & $102(31 \%)$ & $27(24 \%)$ & $75(35 \%)$ & \\
\hline Other & $24(7 \%)$ & $5(5 \%)$ & $19(9 \%)$ & \\
\hline Body-mass index, $\mathrm{Kg} / \mathrm{m}^{2},(\mathrm{SD})$ & $24.6 \pm 3.7$ & $24.2 \pm 3.7$ & $24.5 \pm 3.7$ & 0.82 \\
\hline Balthazar grading standard, n (\%) & & & & 0.13 \\
\hline C- grade & $26(8 \%)$ & $13(12 \%)$ & $13(6 \%)$ & \\
\hline D- grade & $222(67 \%)$ & $76(68 \%)$ & $146(67 \%)$ & \\
\hline E- grade & $81(25 \%)$ & $23(20 \%)$ & $58(27 \%)$ & \\
\hline \multicolumn{5}{|l|}{ Laboratory data } \\
\hline White blood count, $\times 10^{9} / \mathrm{L}$, (SD) & $14.3 \pm 6.8$ & $15.2 \pm 5.4$ & $14.9 \pm 6.3$ & 0.23 \\
\hline Hematocrit, IQR & $43.1(38.9-48.9)$ & $41(36.6-46.1)$ & $44.4(40-50)$ & $<0.01$ \\
\hline Hematocrit $\geq 44, n(\%)$ & $154(47 \%)$ & 35 (31\%) & $119(59 \%)$ & $<0.01$ \\
\hline Serum calcium, mmol/L, & $1.9(1.7-2.1)$ & $2(1.8-2.2)$ & $1.9(1.6-2.1)$ & 0.01 \\
\hline Serum calcium< 2 mmol/L, n (\%) & $182(55 \%)$ & $50(45 \%)$ & $132(61 \%)$ & 0.06 \\
\hline Serum glucose, mmol/L, IQR & $9.3(7.3-12.7)$ & $7.7(6.1-9.7)$ & $10.5(8.0-14.7)$ & $<0.01$ \\
\hline Serum urea, mmol/L, IQR & $7.3(5.0-11.5)$ & $5.7(4.1-9.6)$ & $7.7(5.6-12.4)$ & $<0.01$ \\
\hline Serum creatinine $\geq 1.9$ mg / dl, n (\%) & $74(22 \%)$ & $10(9 \%)$ & $64(29 \%)$ & $<0.01$ \\
\hline Serum albumin & $35 \pm 5.4$ & $35.4 \pm 5.3$ & $34.8 \pm 5.4$ & 0.37 \\
\hline C-reactive protein $\geq 150 \mathrm{mg} / \mathrm{L}, \mathrm{n}(\%)$ & $269(82 \%)$ & $90(80 \%)$ & $179(82 \%)$ & 0.64 \\
\hline Procalcitonin $\geq 3.8$ ng/mL, n (\%) & $142(43 \%)$ & $23(21 \%)$ & $119(55 \%)$ & $<0.01$ \\
\hline $\mathrm{BE} \geq|4| \mathrm{mmol} / \mathrm{L}, \mathrm{n}(\%)$ & $170(52 \%)$ & $30(27 \%)$ & $140(65 \%)$ & $<0.01$ \\
\hline \multicolumn{5}{|l|}{ Severity scores } \\
\hline SIRS scores $\geq 3, n(\%)$ & $128(39 \%)$ & $36(32 \%)$ & $92(42 \%)$ & 0.07 \\
\hline APACHEllscores, IQR & $10(7-13)$ & $9(7-12)$ & $11(8-14)$ & $<0.01$ \\
\hline APACHEllscores $\geq 15, \mathrm{n}(\%)$ & 68 (18\%) & 13 (12\%) & 55 (25\%) & $<0.01$ \\
\hline
\end{tabular}

Data are mean (SD), median (IQR), or $\mathrm{n}(\%)$; SD Standard deviation, IQR Interquartile range, BE Base excess, SIRS Systemic inflammatory response syndrome, APACHE Acute Physiology and Chronic Health Evaluation

Table 2 types of persistent organ failure after $48 \mathrm{~h}$ at admission and different groups by arterial lactate

\begin{tabular}{|c|c|c|c|c|}
\hline Variable & $\begin{array}{l}\text { All patients } \\
(n=329)\end{array}$ & $\begin{array}{l}\text { Normal lactate } \\
(n=112)\end{array}$ & $\begin{array}{l}\text { Elevated lactate } \\
(n=217)\end{array}$ & $P$ value \\
\hline \multicolumn{5}{|l|}{ Single persistent organ failure } \\
\hline Respiratory & $238(72 \%)$ & $99(88 \%)$ & $139(64 \%)$ & $<0.01$ \\
\hline Renal & $17(5 \%)$ & $5(5 \%)$ & $12(6 \%)$ & 0.8 \\
\hline Cardiovascular & $0(0 \%)$ & $0(0 \%)$ & $0(0 \%)$ & 1 \\
\hline \multicolumn{5}{|l|}{ Multiple persistent organ failure } \\
\hline Respiratory + renal & $52(16 \%)$ & $7(6 \%)$ & $45(21 \%)$ & 0.01 \\
\hline Respiratory + cardiovascular & $3(1 \%)$ & $0(0 \%)$ & $3(1 \%)$ & 1 \\
\hline Respiratory + cardiovascular + renal & $19(6 \%)$ & $1(1 \%)$ & $18(8 \%)$ & 0.01 \\
\hline
\end{tabular}


Comparison of types of POF in a week after admission between the normal and elevated groups

Considering that the main cause of early death in SAP is POF [25], we compared the relationship between lactate levels and the types of POF in a week after admission. Table 2 demonstrates that all of 104 (93\%) patients developed a single POF, and the respiratory system was involved in 99 (88\%) patients in the normal group, which is far from the situation in the elevated group, in which 151 (70\%) patients developing a single POF, and the respiratory system was involved in 139 (64\%) patients. However, multiple POF was present in 8 (7\%) patients $(7$ lung and kidney and 1 lung, kidney and heart), which was obviously below the $66(20 \%)$ patients suffering multiple POF in the elevated group (43 lung and kidney, 3 lung and heart, and 18 of lung, kidney and heart). Compared to patients with normal arterial lactate levels, we observed that patients with high arterial lactate have significantly higher incidences of developing multiple POF (7\% vs. $20 \% ; P<0.01$ ).

\section{Comparison of primary and secondary outcomes according to different groups}

Approximately $9 \%$ of patients died in the study. For primary outcomes, we observed significant differences in death $(2 \%$ vs $12 \%, P<0.01)$, septic shock ( $4 \%$ vs $24 \%$, $P<0.01)$ and pancreatic infection $(12 \%$ vs $37 \%, P<0.01)$ between the two groups (Table 3 and Fig. 2). For some of the secondary outcomes, we also observed mean differences, including abdominal compartment syndrome ( $3 \%$ vs $20 \%, P<0.01$ ), pancreatic necrosis $(41 \%$ vs $63 \%$, $P<0.01)$, walled-off necrosis $(6 \%$ vs $21 \%, P<0.01)$,

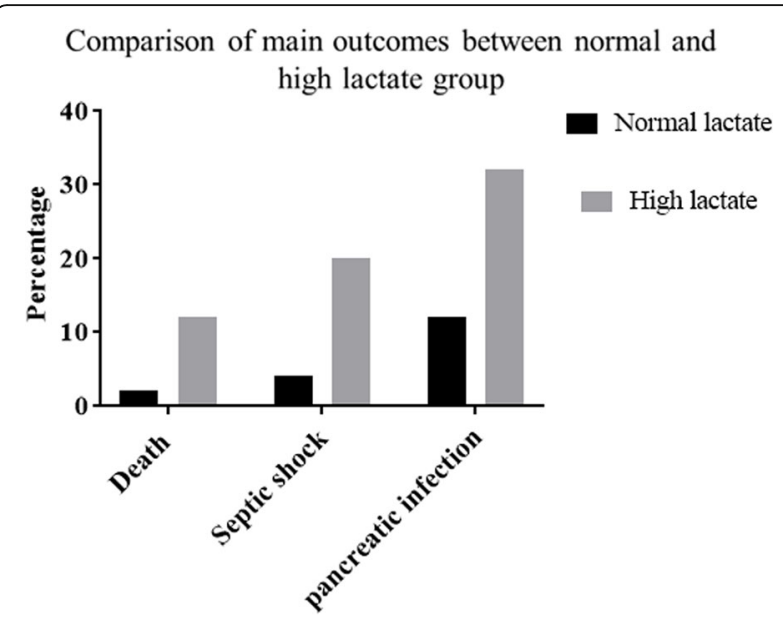

Fig. 2 Main outcomes between normal lactate and high lactate group in severe acute pancreatitis patients

hospital stay $(13(9.5-19)$ vs 19 [13-30], $P=0.01)$, need for ventilator support ( $26 \%$ vs $54 \%, P<0.01)$ and hospital stay in the ICU $(6$ [3-11] vs 10 [5-19], $P<0.01)$. However, for other secondary outcomes, such as portal vein thrombosis, pancreatic fistula, intestinal fistula and diabetes, there was no significant difference (Table 3).

\section{Admission arterial lactate level as an independent prognostic factor for mortality}

To further evaluate the relationship between admission arterial lactate levels and death in SAP, we constructed a multivariate logistic regression analysis model consisting of five parameters (procalcitonin, arterial lactate, APACHE II, hematocrit and serum creatinine). In the

Table 3 Primary and secondary outcomes according to different groups by arterial lactate

\begin{tabular}{|c|c|c|c|c|}
\hline Variable & $\begin{array}{l}\text { All patients } \\
(n=329)\end{array}$ & $\begin{array}{l}\text { Normal } \\
(n=112)\end{array}$ & $\begin{array}{l}\text { High lactate } \\
(n=217)\end{array}$ & $P$ value \\
\hline \multicolumn{5}{|l|}{ Primary outcomes } \\
\hline Death & $28(9 \%)$ & $2(2 \%)$ & $26(12 \%)$ & 0.01 \\
\hline Septic shock & $47(14 \%)$ & $4(4 \%)$ & $43(20 \%)$ & $<0.01$ \\
\hline pancreatic infection & $83(25 \%)$ & $13(12 \%)$ & $70(32 \%)$ & $<0.01$ \\
\hline \multicolumn{5}{|l|}{ Secondary outcomes } \\
\hline Abdominal compartment syndrome & $46(14 \%)$ & $3(3 \%)$ & $43(20 \%)$ & $<0.01$ \\
\hline Pancreatic necrosis & $182(55 \%)$ & $46(41 \%)$ & $136(63 \%)$ & $<0.01$ \\
\hline Walled-off necrosis & $52(16 \%)$ & $7(6 \%)$ & $45(21 \%)$ & $<0.01$ \\
\hline Portal vein thrombosis & $19(6 \%)$ & $4(4 \%)$ & $15(7 \%)$ & 0.32 \\
\hline Pancreatic fistula & $7(2 \%)$ & $0(0 \%)$ & $7(3 \%)$ & 0.1 \\
\hline Intestinal fistula & $8(2 \%)$ & $0(0 \%)$ & $8(4 \%)$ & 0.06 \\
\hline Diabetes & $51(16 \%)$ & $16(14 \%)$ & $35(16 \%)$ & 0.7 \\
\hline Hospital stay, days, IQR & $17(11-28)$ & $13(9.5-19)$ & $19(13-31)$ & 0.01 \\
\hline Need for ventilator support & $146(44 \%)$ & $29(26 \%)$ & $117(54 \%)$ & $<0.01$ \\
\hline Hospital stay in ICU, days, IQR & $8(4-15)$ & $6(3-11)$ & $10(5-19)$ & $<0.01$ \\
\hline
\end{tabular}

Data are median (IQR), or $\mathrm{n}(\%)$; IQR Interquartile range, ICU Intensive care unit, SIRS Systemic inflammatory response syndrome 
multivariate logistic regression model, APACHE II, procalcitonin and arterial lactate levels were significant at $P<0.05$, with hazard ratios 3.5(1.3-9.5), 5.6 (1.5-21.2) and 10 (3.7-27), respectively, listed in Table 4. In addition, the mean arterial lactate level in the nonsurvivor group was clearly higher than in the survivor group in the first $24 \mathrm{~h}$ of hospitalization (5.3 vs 2.4 ), and the trend in arterial lactate levels also different 7 days after enough fluid recovery (Fig. 3).

\section{Summary of indictors for prediction mortality in SAP}

We summarized the sensitivity, specificity and AUC results in predicting mortality for arterial lactate levels as well as additional laboratory tests in Table 5 . All of these parameters are moderately accurate in predicting death in SAP, with an AUC range of 0.69-0.78. For predicting mortality, an arterial lactate level $\geq 4 \mathrm{mmol} / \mathrm{L}$ had the highest accuracy, with a relatively high sensitivity of $71 \%$ and had the highest specificity of $85 \%$, excluding the possibility of mortality. Procalcitonin $\geq 3.8 \mathrm{ng} / \mathrm{ml}$ had the highest sensitivity of $89 \%$ in predicting mortality.

\section{Discussion}

The present study uses a medical database to investigate the association between arterial lactate levels and clinical outcomes in SAP. In this retrospective cohort study, we demonstrated that an initially elevated arterial lactate level was associated with poor outcomes and may be an effective risk-stratification biomarker in patients with SAP. Second, we found that a high arterial lactate level $(\geq 4 \mathrm{mmol} / /$ $\mathrm{L})$ at admission was independently associated with a risk factor for mortality after controlling for the effect of serum urea, procalcitonin, hematocrit, SIRS and APACHE II. Our study showed that an arterial lactate level $\geq 4 \mathrm{mmol} / \mathrm{L}$ on admission for the prediction of mortality in SAP had an AUC of 0.78 (95\% CI: $0.68-0.88$ ), a sensitivity of $71 \%$ and a specificity of $88 \%$ (Table 5). Furthermore, we revealed that arterial lactate levels increased again 7 days after admission after continuous fluid resuscitation in patients in the nonsurvivor group. By contrast, patients in the survivor group had normal arterial lactate levels.

Peery AE et al. reported that AP is an important cause of death and a medical burden in gastrointestinal diseases, and the overall population mortality has been
Mean arterial lactate level among survivors versus nonsurvivors in seven days

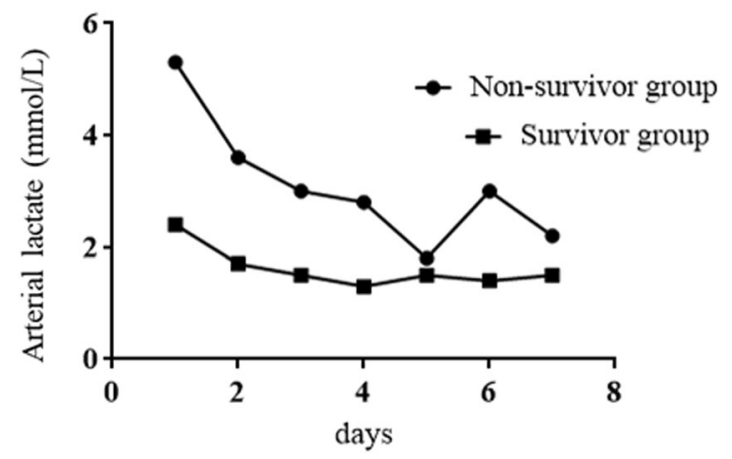

Fig. 3 Levels and trends of arterial between survivor group and non-survivor group for severe acute pancreatitis patients in 7 days

unchanged in the United States [26]. Thus, AP remains a large challenge for clinicians. In 2010, a systematic review involving fourteen studies proved that organ failure and infected pancreatic necrosis were determinants of mortality in patients with AP, especially in cases of critical acute pancreatitis [25]. This implies that the ability to risk-stratify patients during the most proximal phase of SAP is of great importance for determining the need for initial intensive care and other therapeutic strategies. However, current prognostic markers in SAP have some limitations. First, the primary outcomes for most of the previously studied markers and system scores were necrosis or organ failure, rather than mortality, septic shock and pancreatic infection, which are too inconvenient to use in clinical practice to determine system scores $[10,11,13,15]$. Inflammatory markers such as Creactive protein and procalcitonin may be useful in predicting severity. However, it takes a great deal of time to receive the results [12]. Therefore, it is necessary to further explore new markers.

We chose the arterial lactate level as a potential marker of poor prognosis in SAP for several reasons. First, lactate is a routine laboratory marker that can both reflect the degree of tissue hypoxia and the changes in intravascular volume status. Second, as a laboratory test, a lactate measurement can be accomplished quickly with the advantages of low cost and high reproducibility.

Table 4 Uni- and multi-variate logistic regression analyses of risk factors for mortality

\begin{tabular}{lllll}
\hline Variables & Univariate analysis Hazard ratio $(95 \% \mathrm{Cl})$ & $P$-value & Multivariate analysis Hazard ratio $(95 \% \mathrm{Cl})$ & $P$-value \\
\hline Procalcitonin $\geq 3.8 \mathrm{ng} / \mathrm{ml}$ & $13.1(3.9-44.6)$ & $<0.01$ & $5.6(1.5-21.2)$ & 0.01 \\
APACHEllscore $\geq 15$ & $6.4(2.9-14.3)$ & $<0.01$ & $3.5(1.3-9.5)$ & 0.02 \\
Arterial lactate $\geq 4 \mathrm{mmol} / / \mathrm{L}$ & $14.2(5.9-34.5)$ & $<0.01$ & $10(3.7-27)$ & $<0.01$ \\
Hematocrit $\geq 44$ & $1.2(0.4-1.8)$ & 0.66 & $0.4(0.2-1.3)$ & 0.89 \\
Serum creatinine $\geq 1.9 \mathrm{mg} / \mathrm{dl}$ & $5.6(2.5-12.4)$ & $<0.01$ & $1.5(0.6-4)$. & 0.28 \\
\hline
\end{tabular}

Abbreviations; APACHE Acute Physiology and Chronic Health Evaluation 
Table 5 Sensitivity, specificity and AUC of different indicators in predicting mortality in SAP

\begin{tabular}{|c|c|c|c|c|c|}
\hline \multirow{2}{*}{$\begin{array}{l}\text { Laboratory } \\
\text { Markers }\end{array}$} & \multicolumn{2}{|c|}{ Mortality } & \multirow{2}{*}{$\begin{array}{l}\text { Sensitivity } \\
(\%)\end{array}$} & \multirow{2}{*}{$\begin{array}{l}\text { Specificity } \\
(\%)\end{array}$} & \multirow{2}{*}{$\begin{array}{l}\text { AUC } \\
(\%)\end{array}$} \\
\hline & Yes & No & & & \\
\hline \multicolumn{6}{|l|}{ Arterial lactate } \\
\hline$\geq 4 \mathrm{mmol} / / \mathrm{L}$ & 20 & 45 & 71 & 85 & 0.78 \\
\hline$<4 \mathrm{mmol} / / \mathrm{L}$ & 8 & 256 & & & \\
\hline \multicolumn{6}{|l|}{ Serum creatinine } \\
\hline$\geq 1.9 \mathrm{mg} / \mathrm{dl}$ & 16 & 58 & 57 & 81 & 0.69 \\
\hline$<1.9 \mathrm{mg} / \mathrm{dl}$ & 12 & 243 & & & \\
\hline \multicolumn{6}{|l|}{ Procalcitonin } \\
\hline$\geq 3.8 \mathrm{ng} / \mathrm{ml}$ & 25 & 117 & 89 & 61 & 0.75 \\
\hline$<3.8 \mathrm{ng} / \mathrm{ml}$ & 3 & 184 & & & \\
\hline \multicolumn{6}{|l|}{ APACHEIl scores } \\
\hline$\geq 15$ & 16 & 52 & 57 & 83 & 0.7 \\
\hline$<15$ & 12 & 249 & & & \\
\hline
\end{tabular}

Abbreviations; APACHE Acute Physiology and Chronic Health Evaluation,

Third, as we mentioned above, in many studies, high lactate concentration portended a bad outcome in cases of critical illness, including septic shock, severe sepsis, organ failure, trauma, AP and other disease [17, 18, 22, 27]. All of those observations suggest that initially elevated arterial lactate levels may be a simple marker to risk-stratify patients with SAP in the early stages of the disease.

An important finding in our study supports the conjecture that an initially elevated arterial lactate level portends a bad outcome in SAP (Tables 2, 3). There are several possible explanations for this outcome. First, it is well known that an important reason for the worsening of AP is that insufficient blood volume, due to various causes, increases hypoperfusion of the pancreas and other vital organs, leading to pancreatic necrosis and organ dysfunction [28]. We believe that the admission arterial lactate level may reflect the underlying state of intravascular volume scarcity and vital organ perfusion (including kidney, gut, liver and even heart). Conversely, the damage to major organ functions further increases the level of arterial lactate through impaired lactate clearance and excessive production [27, 29]. Second, lactate has been regarded as a marker of tissue hypoxia in critically ill patients $[21,30]$. The main function of the lung is to supply oxygen to tissues. Thus, lactate is likely to represent the degree of pulmonary failure. Persistent pulmonary failure is usually the direct cause of death in SAP. Third, lactate is also considered an early biomarker of the response to inflammatory mediators [31-33]. Lactic acid may indicate the extent of the inflammatory response in SAP. Mofidi R et al. found that persistent SIRS is associated with multiple organ dysfunction syndrome and death in patients with acute pancreatitis and is an early indicator of the likely severity of acute pancreatitis [6]. Fourth, patients with SAP have high energy metabolism $[19,34]$, which may be achieved by increasing aerobic glycolysis. If the amount of pyruvic acid produced by aerobic glycolysis exceeds the metabolic capacity of pyruvate dehydrogenase, it will lead to the accumulation of lactate. Levy et al. revealed that elevated lactate may be associated with increasing $\mathrm{Na}^{+} \mathrm{K}^{+}$ATPase activity in septic shock patients [21]. Therefore, lactate may also reflect the state of energy metabolism in SAP. Regardless of the specific mechanism involved, our research clearly showed that patients with elevated arterial lactate levels with early-stage SAP have an increased risk of mortality and of both mild and serious complications.

The second important finding in our research is that the average arterial lactate level in the mortality group increased again after adequate volume resuscitation (Fig. 3). This may reflect a failure of fluid resuscitation and may indicate the state of organ function, which involves lactate clearance and production. Haas SA reported that patients with a lactate clearance of less than $30 \%$ within the first $12 \mathrm{~h}$ had a very poor prognosis with an ICU mortality of almost 100\% [18].

Our study is clearly limited in several aspects. First, this is a retrospective study, which is potentially prone to selection bias. To minimize the possibility of selection bias, we adopted strict inclusion criteria and expanded the sample size as much as possible $(N>300)$. Second, some patients received repeated measurements of lactate in $24 \mathrm{~h}$ based on the condition of the disease, and we took the initial value on the first day and the highest value during the following 6 days. We adopted the approach that the mean value and the lactate value on the next day must be separated by $6 \mathrm{~h}$ to reduce this impact. Third, some patients received rehydration therapy before admission. Finally, we followed up 1 month after the patient was discharged from the hospital, which may be too short a timeframe to adequately assess primary and secondary outcomes.

Despite these limitations, this retrospective study can provide effective information on treatment strategies. First, initially elevated admission arterial lactate levels may be a signal that patients in SAP are at risk for poorer outcomes and need to undergo aggressive resuscitation. For several decades, many clinical trials have shown that aggressive hydration may be associated with reduced morbidity and mortality [35-37]. Second, serial measurements of arterial lactate levels may offer valuable clinical information on disease progression.

\section{Conclusions}

In summary, our research demonstrates that initially an elevated arterial lactate level is associated with morbidity 
and mortality in SAP. Additionally, serial monitoring of lactate levels may provide important information about disease progression. Based on the results of this study, the measurement of arterial lactate may be a useful, simple, rapid way to identify high-risk patients with SAP. Certainly, a large sample and prospective studies are needed to further confirm our results.

\section{Acknowledgments}

Not applicable.

\section{Authors' contributions}

WQS conceived the study; WQS, WHH, YZ1, YZ2, HZ, PL, LX and NHL participated in the study design; WQS collected the data; WQS, JHW and JC performed the statistical analyses; WQS and JHW $n$ drafted the manuscript; LX edited and checked the manuscript. The authors have read and approved the final manuscript.

\section{Funding}

The study design and data collection were funded by the National Natural Science Foundation of China (No: 81760121), the Science and Technology Plan Grant (No. 20165092) from the Health Department of Jiangxi Province, China, and the Science and Technology Plan Grant (Key project) (No. GJJ160024) from the Education Department of Jiangxi Province, China, Graduate Innovation fund of Jiangxi Province (YC2018-S117).

\section{Availability of data and materials}

All data generated or analyzed during this study are included in this published article [and its supplementary information files].

\section{Ethics approval and consent to participate}

The study was approved by the ethics committee of The First Affiliated Hospital of Nanchang University (No. 2011001). The study obtained the verbal consent from study participants which approved by the ethics committee of The First Affiliated Hospital of Nanchang University

\section{Consent for publication}

Not Applicable.

\section{Competing interests}

The authors declare that they have no competing interests. No writing assistance was provided in the production of this manuscript.

Received: 1 June 2019 Accepted: 5 April 2020

Published online: 19 April 2020

\section{References}

1. Banks PA, Bollen TL, Dervenis C, et al. Classification of acute pancreatitis-2012: revision of the Atlanta classification and definitions by international consensus. Gut. 2013:62:102-11.

2. Tenner S, Baillie J, DeWitt J, et al. American College of Gastroenterology guideline: management of acute pancreatitis. Am J Gastroenterol. 2013;108: 1400-15 1416

3. Forsmark CEVSWC. Acute Pancreatitis. N Engl J Med. 2016:375(20):1272-981.

4. Larvin M, McMahon MJ. APACHE-II score for assessment and monitoring of acute pancreatitis. Lancet. 1989:2:201-5.

5. Papachristou GI, Muddana V, Yadav D, et al. Comparison of BISAP, Ranson's, APACHE-II, and CTSI scores in predicting organ failure, complications, and mortality in acute pancreatitis. Am J Gastroenterol. 2010;105:435-41 quiz 442.

6. Mofidi R, Duff MD, Wigmore SJ, et al. Association between early systemic inflammatory response, severity of multiorgan dysfunction and death in acute pancreatitis. Br J Surg. 2006:93:738-44.

7. Singh VK, Wu BU, Bollen TL, et al. Early systemic inflammatory response syndrome is associated with severe acute pancreatitis. Clin Gastroentero Hepatol. 2009;7:1247-51.

8. Wu BU, Johannes RS, Sun X, et al. Early changes in blood urea nitrogen predict mortality in acute pancreatitis. Gastroenterology. 2009;137:129-35.
9. Shinzeki M, Ueda T, Takeyama Y, et al. Prediction of early death in severe acute pancreatitis. J Gastroenterol. 2008:43:152-8.

10. Koutroumpakis E, Wu BU, Bakker OJ, et al. Admission hematocrit and rise in blood urea nitrogen at $24 \mathrm{~h}$ outperform other laboratory markers in predicting persistent organ failure and pancreatic necrosis in acute pancreatitis: a post hoc analysis of three large prospective databases. Am J Gastroenterol. 2016;111:1216.

11. Muddana V, Whitcomb DC, Khalid A, et al. Elevated serum creatinine as a marker of pancreatic necrosis in acute pancreatitis. Am J Gastroenterol. 2009;104:164-70.

12. Rau BM, Kemppainen EA, Gumbs AA, et al. Early assessment of pancreatic infections and overall prognosis in severe acute pancreatitis by procalcitonin (PCT): a prospective international multicenter study. Ann Surg. 2007;245:745-54.

13. Cardoso FS, Ricardo LB, Oliveira AM, et al. C-reactive protein prognostic accuracy in acute pancreatitis: timing of measurement and cutoff points. Eur J Gastroenterol Hepatol. 2013;25:784-9.

14. Ranson JH, Rifkind KM, Roses DF, et al. Prognostic signs and the role of operative management in acute pancreatitis. Surg Gynecol Obstet. 1974; 139:69-81.

15. Mounzer R, Langmead CJ, Wu BU, et al. Comparison of existing clinical scoring systems to predict persistent organ failure in patients with acute pancreatitis. Gastroenterology. 2012;142:1476-82 quiz e15-6.

16. Bakker J, Gris P, Coffernils M, et al. Serial blood lactate levels can predict the development of multiple organ failure following septic shock. Am J Surg. 1996;171:221-6.

17. Freire JP, Wieringa $\mathrm{N}$, de Felice $\mathrm{E}$, et al. The association of early combined lactate and glucose levels with subsequent renal and liver dysfunction and hospital mortality in critically ill patients. Crit Care. 2017;21:218.

18. Haas SA, Lange T, Saugel B, et al. Severe hyperlactatemia, lactate clearance and mortality in unselected critically ill patients. Intensive Care Med. 2016; 42:202-10.

19. Jansen TC, van Bommel J, Bakker J. Blood lactate monitoring in critically ill patients: a systematic health technology assessment. Crit Care Med. 2009;37: 2827-39.

20. Casserly B, Phillips GS, Schorr C, et al. Lactate measurements in sepsisinduced tissue hypoperfusion: results from the surviving Sepsis campaign database. Crit Care Med. 2015:43:567-73.

21. Levy B, Gibot S, Franck P, et al. Relation between muscle Na+K+ ATPase activity and raised lactate concentrations in septic shock: a prospective study. Lancet. 2005;365:871-5.

22. Valverde-Lopez F, Matas-Cobos AM, Alegria-Motte C, et al. BISAP, RANSON, lactate and others biomarkers in prediction of severe acute pancreatitis in a European cohort. J Gastroenterol Hepatol. 2017;32:1649-56.

23. Chinese Society of Critical Care Medicine. Chinese guidelines for management of severe sepsis and septic shock 2014. Zhonghua Wei Zhong Bing Ji Jiu Yi Xue. 2015:27:401-26.

24. Malbrain ML, Cheatham ML, Kirkpatrick A, et al. Results from the international conference of experts on intra-abdominal hypertension and abdominal compartment syndrome. I Definitions. Intensive Care Med. 2006; 32:1722-32.

25. Petrov MS, Shanbhag S, Chakraborty M, et al. Organ failure and infection of pancreatic necrosis as determinants of mortality in patients with acute pancreatitis. Gastroenterology. 2010;139:813-20.

26. Peery AF, Crockett SD, Barritt AS, et al. Burden of Gastrointestinal, Liver, and Pancreatic Diseases in the United States. Gastroenterology. 2015;149:17311741.e3.

27. Mikkelsen ME, Miltiades AN, Gaieski DF, et al. Serum lactate is associated with mortality in severe sepsis independent of organ failure and shock*. Crit Care Med. 2009:37:1670-7.

28. Takeda K, Mikami Y, Fukuyama S, et al. Pancreatic ischemia associated with vasospasm in the early phase of human acute necrotizing pancreatitis. Pancreas. 2005;30:40-9.

29. Revelly JP, Tappy L, Martinez A, et al. Lactate and glucose metabolism in severe sepsis and cardiogenic shock. Crit Care Med. 2005;33:2235-40.

30. Ronco JJ, Fenwick JC, Tweeddale MG, et al. Identification of the critical oxygen delivery for anaerobic metabolism in critically ill septic and nonseptic humans. JAMA. 1993:270:1724-30.

31. Routsi C, Bardouniotou H, Delivoria-loannidou V, et al. Pulmonary lactate release in patients with acute lung injury is not attributable to lung tissue hypoxia. Crit Care Med. 1999;27:2469-73. 
32. Rivers EP, Kruse JA, Jacobsen $\mathrm{G}$, et al. The influence of early hemodynamic optimization on biomarker patterns of severe sepsis and septic shock. Crit Care Med. 2007;35:2016-24.

33. Haji-Michael PG, Ladriere L, Sener A, et al. Leukocyte glycolysis and lactate output in animal sepsis and ex vivo human blood. Metabolism. 1999;48: 779-85.

34. Ong JP, Fock KM. Nutritional support in acute pancreatitis. J Dig Dis. 2012; 13:445-52.

35. Wall I, Badalov N, Baradarian R, et al. Decreased mortality in acute pancreatitis related to early aggressive hydration. Pancreas. 2011;40:547-50

36. Yamashita T, Horibe M, Sanui M, et al. Large volume fluid resuscitation for severe acute pancreatitis is associated with reduced mortality: a multicenter retrospective study. J Clin Gastroenterol. 2018;12(3):124-9.

37. Gardner TB, Vege SS, Chari ST, et al. Faster rate of initial fluid resuscitation in severe acute pancreatitis diminishes in-hospital mortality. Pancreatology. 2009;9:770-6.

\section{Publisher's Note}

Springer Nature remains neutral with regard to jurisdictional claims in published maps and institutional affiliations.

Ready to submit your research? Choose BMC and benefit from:

- fast, convenient online submission

- thorough peer review by experienced researchers in your field

- rapid publication on acceptance

- support for research data, including large and complex data types

- gold Open Access which fosters wider collaboration and increased citations

- maximum visibility for your research: over $100 \mathrm{M}$ website views per year

At BMC, research is always in progress.

Learn more biomedcentral.com/submissions 